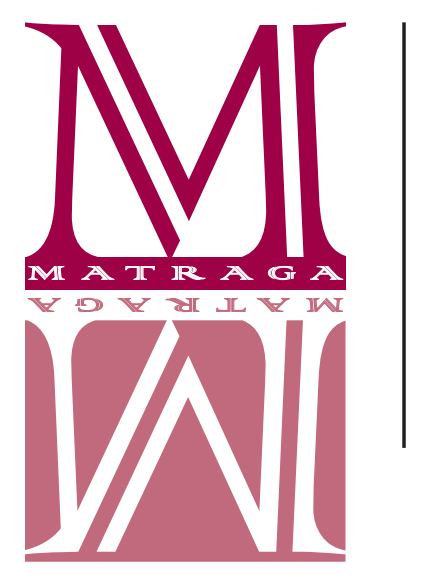

\title{
Toda a rudeza, na verdade, é calma
}

\author{
Marcus Freitas \\ Universidade Federal de Minas Gerais/CNPq
}

https://orcid.org/0000-0003-2205-0167

\section{RESUMO}

Este artigo analisa o livro Poema algum basta, de Maria Amélia Dalvi, com vistas à exposição de sua poética. Em oposição ao que, na poética contemporânea, se pode chamar de metapoesia das coisas, combinação dos legados da Poesia Concreta e da Poesia Marginal, Dalvi faz um salto sobre essas linhas de força em direção à grande tradição modernista, que aproxima construtivismo e engajamento, arte e política, como descreve Silviano Santiago através do conceito de "literatura anfíbia". Nesse passo, pode-se dizer que a escritora constrói uma "poética da educação", na qual se encontram presentes tanto a atribuição de função pedagógica ao intelectual em um mundo distópico, quanto a miragem de um horizonte puro, construído pelo trabalho paciente sobre a forma poética depurada. O artigo aproxima ainda as imagens recorrentes da montanha e do mar na poesia de Maria Amélia Dalvi com o hexagrama 4 do / Ching, Imaturidade, cujo tema é a educação.

PALAVRAS-CHAVE: Poesia; Engajamento; Educação; / Ching.

\section{All Rudeness, Actually, Is Calm ABSTRACT}

This article aims at analysing the poetics of education in Maria Amélia Dalvi's Poema algum basta (No Poem Stands Alone). In opposition to what may be paradoxally named "metapoetry of things", a recent poetic tradition which combines the legacies of the Brazilian Concretism and the so called Marginal Poetry, Dalvi's work lays down its roots back into the Brazilian Modernism, specially its "amphibious" quality of entangling construtivism and engagment (as pointed out by the literary critic Silviano Santiago). In such poetics of education, Dalvi, both as poet and intelectual, merges a self-attribution of pedagogical character with the poetic task of building a pure form, an artistic construction against a dystopian world. This article also aproximates recurrent images of sea and mountain within Dalvi's work to the Hexagram 4th in the I Ching, named Imaturity, which main image is education.

KEYWORDS: Poetry; Engagement; Education; / Ching. 
$\mathrm{M}$ aria Amélia Dalvi estreou em livro, como poeta, ao final de 2019, com Poema algum basta (DALVI, 2019, 100 p.). Em uma década marcada pela poesia produzida por mulheres, seria quase natural tentar, por semelhanças e contrastes, enquadrar o livro no conjunto da poesia brasileira contemporânea de autoria feminina. Prefiro, entretanto, uma abordagem ao mesmo tempo mais modesta e mais vertical, um relatório de impressões de leitura, com vistas ao estabelecimento de uma poética e de sua diferença específica, para compreender o lugar dessa voz poética em relação às tradições de composição que podem ser rastreadas na poesia brasileira desde o Modernismo. Mesmo que a atividade crítica aqui seja compreendida como teoria, e não como guia de leitura (uma vez que se trata de análise, e não de resenha), não é ocioso, desde já, avisar ao leitor que se trata de uma voz vigorosa, nítida e singular na nossa paisagem poética. Esse vigor deriva, possivelmente, de longa maturação antes da estreia.

Estamos diante de uma autora que, na construção de sua poesia, parece seguir o conselho de Horácio: limae labor et mora, ou seja, que se pauta pela combinação do trabalho da lima com o da passagem do tempo. O poeta, no sentido horaciano, deve esperar que o tempo mostre os excessos a serem limados no poema. Na metáfora temporal de Horácio, o poeta precisa reprovar (guardar consigo) os poemas que não tenham consumido muitos dias de reescrita, e cuja correção tenha durado no mínimo o tempo de aparar-se dez vezes as unhas: "carmen reprehendite quod non multa dies et multa litura coercuit atque praesectum deciens non castigauit ad unguem", ou seja "reprovai o carme que muitos dias e muita risca não consumiram e corrigiram até a unha aparada dez vezes" (MACIEL et all, 2013, p. 36/37). Aqui, a apara e o polimento das unhas surge como imagem da apara e do polimento dos versos. Entretanto, polir demais constitui erro, pois pode-se desgastar o que se encontrava perfeito. Da mesma maneira, pela passagem do tempo permanecerão apenas os versos que se mostrem duradouros. Assim, à defesa da justa medida se alia o elogio da espera e do senso de oportunidade. Nada de pressa em publicar, melhor permanecer por um tempo em silêncio, enquanto os versos decantam, e sua forma se depura. Já no século XVI, António Ferreira nos dá um outro exemplo. Na "Carta XII a Diogo Bernardes", Ferreira retoma o mote horaciano e dá ao jovem poeta Bernardes o mesmo conselho: "Não queiras de ti logo contentar-te,/ É necessário ser um tempo mudo!/ Ouvir, e ler somente: que aproveita/ Sem armas, com fervor cometer tudo?” (FERREIRA, citado em SPINA, 1967, p. 11). Trata-se de uma educação poética baseada em poética da educação (antes ouvir e ler, para daí preparar suas armas).

O duplo tema não comparece por acaso. Tomemos um biografema como fio condutor. Maria Amélia Dalvi ensina literatura e educação na Universidade Federal do Espírito Santo, e dedica sua grande capacidade de pesquisa exatamente às relações entre esses dois campos de atividade. Se, por um lado, ao contrário da maioria dos poetas, a autora foi "morosa" (no sentido horaciano) ao publicar seus poemas, por outro lado a intelectual e educadora agiu sempre com verdadeiro furor intelectual. Tendo entrado para a graduação em Letras aos 17 anos, aos 27 já era doutora e professora da UFES. Hoje, aos 37 anos, quando traz à prensa sua primeira coleção de poemas, trata-se de uma das intelectuais mais produtivas e perspicazes de sua geração no país. Desse biografema, podemos retirar uma hipótese de leitura do livro.

No percurso da autora, a inversão quiasmática do furor poético e da dedicação intelectual, vertidos em furor intelectual e dedicação poética, aponta para a construção de uma poesia medi- 
tada, que recusou a distribuição esporádica de versos, mesmo que fossem bons, em favor de um acúmulo de aprendizado com mais sentido. Vejamos um metapoema bastante representativo:

\section{PERDA}

nenhum poema sozinho presta, versos de pedra não bastam. é preciso um sentimento ferino e uma voz pessoal, firme, ousada que sustente o desejo, dividindo-o (a página impressa tanto melhor quando entre pessoas dispersa).

tendência neurótica, vaidade, aquele perfil histérico, no mínimo o corte perspectivo histórico, certo acúmulo de leitura que se faz carne. algum pendor entre mártir e suicida são bem-vindos: melhor, requeridos.

poeta algum com suas palavras e umbigo basta, a menos, claro, que morra jovem e seja, óbvio, bem promissor e bonito (quem escreve, mesmo, disso bem sabe) - aí, qualquer defeito à obra se perdoa, as pessoas precisam de quem as salve, novidade exclusiva que as dignifique

(quem quer por à prova o cadáver?)

Se a disposição horaciana se revela patente no "acúmulo de leitura que se faz carne", muito distante está a autora da subserviência às suas leituras. Longe dela o recurso ao intertexto, à citação, à paródia ou à estilização, mecanismos tão comuns em poetas estreantes. Patenteados pelo Alto Modernismo, e diluídos por um século de repetições, esses mecanismos batidos se consagraram como o oposto da voz pessoal, firme e ousada que Maria Amélia exige de si mesma e de qualquer poeta. Em Poema algum basta, a educação poética opera como uma espécie de cadinho em que todos os ingredientes foram macerados ao ponto de não poderem ser reconhecidos, para daí surgir um elemento sui generis, de todo novo. À frente, voltarei ao motivo da educação. Por hora, quero chamar a atenção para a coesão significativa das relações entre a camada fonético-morfológica e a verticalidade semântica que percorrem todo o livro.

Do poema 'Perda", tomo como mote para a leitura do conjunto a expressão "versos de pedra", e aponto desde já a obsessão, quase "tendência neurótica", do retorno da palavra "pedra" - e de seu anagrama "perda" (título do poema) - ao longo do livro, além de sua disseminação em palavras outras que se estruturam no encontro sonoro de /p/, /d/ e/r/, com suas variantes, inver- 
sões e contaminações sonoras. Essa célula sonora obsessiva, constituída de dois sons oclusivos e um vibrante, às vezes um sibilante $(/ \mathrm{s} / \mathrm{,} / \mathrm{v} / \mathrm{ou} / \mathrm{f} /)$, às vezes ecoando apenas no primeiro deles, /p/, parece indiciar uma obstrução a ser contornada. Tal obstáculo exige do leitor, no plano do poema, um aprendizado de dicção homólogo ao aprendizado do sujeito num mundo que o constrange e ameaça. Senão, vejamos. Desde o título do poema acima, "Perda", pode-se ver a série se impondo: PeRDa, Poema, PResTa, PeDRa, PReCiso, PeSSoal, Página, imPReSSa, PeSSoas, DisPerSa, PeRFil, PeRSPecTivo, PenDor, PoeTa, PalaVRas, PRomiSSoR, PeRDoa, PReCisam, PôR, PRoVa. Quem se deixa levar por uma escuta do livro de Maria Amélia tropeça a cada instante nas variantes desse encontro sonoro carregado de obstrução. Vejamos o poema de abertura do livro, soneto que funciona como emblema dessa obsessão de sua escrita e de seus motivos:

\section{MONTANHA}

Eu vou parir uma montanha

(Arnaldo Antunes,

na voz de Marina Lima)

O ser mais íntimo de uma pedra

- origem e substância mineral -

anuncia ao mundo sua história;

mil milênios, e a existência começa.

Importa ao modo bruto da montanha

(isso lá é das sutilezas que o duro guarda)

postar-se no chão, bem perto do céu:

toda a rudeza, na verdade, é calma.

Cada camada fina de sedimentos

- amontoados frenéticos de células -

se deixa calcária esculpindo o cume.

Em paralelo, se desintegra erodida

para o chão, para o nada, ao rés da vida,

tudo o que anuncia o tempo: coisa impura.

A palavra "pedra", colocada logo no primeiro verso, dispara por todo o poema aquelas variantes da célula sonora antes apontada (pdr, prd, ptr, prt, pr, dtr, dr, rd, rdd, prs, pvr, prv, entre outras), em palavras tais como importa, bruto, duro, guarda, postar-se, perto, rudeza, verdade, paralelo, desintegra, erodida, para, rés, impura. Podemos ver que, até na escolha da epígrafe, a obsessão se revela em "parir". O primeiro terceto explica, pela metáfora geológica, o processo de composição: os amontoados frenéticos daquelas células sonoras acumulam uma camada fina de sedimentos que, calcária, ao mesmo tempo esculpe o cume e se desintegra em direção ao mundo, ao tempo, à história, ao chão, à vida, às coisas impuras, ao nada. Cume e chão são imagens complementares do poema, que opera por composição e decomposição. Se o poema, por um lado, se ergue como cume (pedra), miragem ansiada de estabilidade e permanência diante da miséria do mundo e da desintegração das coisas pelo tempo (perda), já por outro lado, a sua 
composição, enquanto testemunho da vida como perda e da história como lugar do humano, deriva daquela mesma decomposição em sedimentos da matéria bruta da pedra. Se o primeiro poema do livro se intitula "Montanha", ao virar a página o leitor encontra "Beira Mar", complemento do anterior, que diz em seus primeiros versos:

\author{
É uma avenida que divide \\ de um lado navio, de outro palácio \\ a senha deste coração que nunca \\ sabe se reina soberano ou flutua.
}

O eu-lírico se vê dividido entre a montanha e o mar, entre reinar soberano ou deixar-se flutuar; entre ficar estático e vertical, postado no chão, ou flutuar na horizontalidade do tempo, dividido entre composição e decomposição. E note-se que a dupla operação de composição e decomposição se dá tanto nos planos fonológico e morfo-sintático, quanto na dimensão semântica do poema. São operações em paralelo, como indica o último terceto de "Montanha".

A alternância física entre movimento horizontal e vertical no interior da paisagem, entre o mar e a pedra - como se o eu-lírico alternasse caminhadas e escaladas - , funciona como imagem concreta da articulação entre relações sintagmáticas e paradigmáticas no interior do poema, colocadas entre o eixo material e combinatório, por um lado, e o eixo semântico, por outro. Para dizer com Roman Jakobson (1985, p. 130), a poesia de Maria Amélia Dalvi expressa com precisão o caráter da função poética, qual seja, o de projetar o princípio de equivalência do eixo de seleção (vertical, semântico e metafórico - Montanha/Pedra) sobre o eixo de combinação (horizontal, morfo-sintático, metonímico - Mar/Perda). O mais revelador do trabalho poético ali presente é o fato de que essas combinações, como em toda grande poesia, não operam simplesmente como mecanismos internos de composição. Ao contrário, projetam-se do eu-lírico para o mundo, no mesmo instante em que trazem o mundo existencial e histórico para dentro do poema, ao localizar o eu-lírico numa encruzilhada entre o ser ("o ser mais íntimo de uma pedra/ origem e substância mineral") e a história ("anuncia ao mundo a sua história").

De fato, a poesia de Maria Amélia Dalvi se quer profundamente engajada na compreensão do sujeito e da história, preocupada com a condição existencial num mundo violento e insano. Essa adesão à realidade, entretanto, não tem caráter conteudístico, conceitual ou panfletário, pois se dá sobretudo por uma internalização das tensões existenciais e sociais como forma poética.

O poema "Penedo" sintetiza uma vez mais toda essa espécie de dialética do sujeito entre o horizonte silencioso da essência e a flutuação inconstante do mar da história e da vida:

\title{
PENEDO
}

Eu me sinto assim, um sujeito feito do bruto, de beleza e altura: um sujeito sem data, tão fundo banhado num mar escuro. (Meu nome inteiro é Penedo.) 
Essas águas geladas, estranhas, dão passagem aos navios -

vejo que pescam, há murmúrio, pessoas que vão sempre de luto.

(Sim, sou grande, com medo.)

O sujeito essencial ("bruto", "alto" e "fundo"), sem história ("sem data"), se justapõe a um mar escuro, cujas águas dão passagem ao que flutua ("navios", "pessoas"), à atividade da vida (a pesca e os murmúrios). As duas dimensões não se descolam. E cabe destacar que as pessoas vão sempre de "luto", marcadas pela perda. Uma vez mais, pedra e perda integram o jogo combinatório de forma e mundo. Ao lermos a microestilística fonológica dos jogos de palavras, das inversões que de "pedra" levam a "perda", do encadeamento sequencial de sons, sílabas e versos cheios de obstáculos de dicção, estamos lendo a imagem poética desse sujeito dividido entre essência e existência, atemporalidade e história, paz e guerra, obstáculo e fluxo.

Em "Manguinhos", outro poema à beira d'água, as mesmas imagens se repetem, agora com o mar em foco, e não mais a pedra, em uma espécie de espelhamento daquela vista anterior:

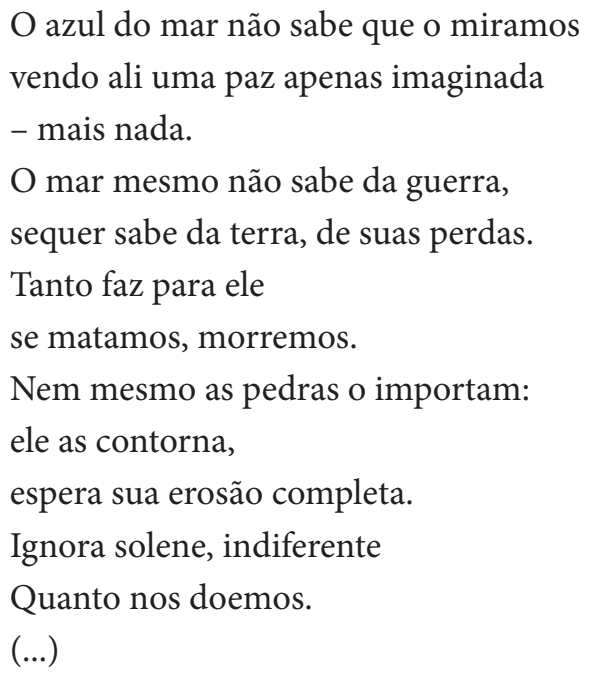

Aqui, de maneira invertida e complementar em relação ao poema anterior, é o mar que se posta solene e indiferente. As pedras em erosão, ao contrário, figuram a imagem do movimento, da terra, da guerra, da perda, em demonstração muito clara da dialética de composição e decomposição para a qual chamamos a atenção.

O livro Poema algum basta deixa à mostra em sua própria organização esse movimento combinatório do estático e do dinâmico, entre um anseio contemplativo e uma ética da ação (que vai se encontrar com o tema da educação), entre o essencial e o contingente. Os poemas se distribuem em quatro partes: 1) Paisagem; 2) Exercício; 3) Substância; 4) Impermanência. Basta ver os títulos das seções para perceber que duas delas se intitulam pelo próprio par distintivo que, desde o primeiro poema do livro, indicam a sua tensão interna, Substância e Impermanência. Estão ali a dizer "ser" e "tempo". Se o leitor voltar aos versos iniciais de "Montanha", antes mostrados, verá que lá está o ser mais íntimo de uma pedra, origem e substância mineral que 
anuncia ao mundo sua história, imagem acabada do par Substância e Impermanência. Os outros dois títulos, Paisagem e Exercício, são variantes da mesma tensão, uma vez que o primeiro tem sentido contemplativo, e o segundo aponta para a ação. A princípio, as seções parecem agrupar poemas por temas: as projeções do eu-lírico sobre a natureza, em Paisagem; contundente crítica política e social, em Exercício; poética, em Substância; e amor, em Impermanência. Mas não custa lembrar, uma vez mais, que essa divisão em partes não separa aqueles dois movimentos antes apontados, apenas dá a ver no plano organizacional um dado da poética. Em todas as partes do livro, os poemas são ao mesmo tempo operações formais e existenciais, seriamente políticos e rigorosamente compostos, jogando por terra qualquer pretensão de vê-los como uma poética fendida entre forma e engajamento, entre ser e história.

Silviano Santiago, em "Uma literatura anfíbia" (2004, p. 64-73), mostra com agudeza a tensão que percorre a literatura brasileira, desde o Modernismo, entre arte e política, estética e ética. Sem nomear autores, o crítico explora uma corrente subterrânea que se deixa ver, por exemplo, na divisão feita por João Cabral de Melo Neto em sua própria obra, ao nomear a reunião de seus poemas, editada em 1956, como Duas Águas, uma construtiva e outra participante; ou por Drummond, na clara passagem de Rosa do Povo a Claro Enigma. Nos dois casos exemplares, aquela tensão nunca separa as dimensões ética e estética. Cabral faz poemas construtivos sobre motivos sociais e políticos; Drummond, ao superar o simples engajamento, jamais cede a qualquer formalismo vazio. A título de exemplo, lembro aqui dois textos críticos que, por caminhos distintos, demonstram essa conjugação de elementos apontada por Silviano. Décio Pignatari, um dos poetas-críticos do concretismo, mostra em detalhe a conjugação de conteúdo e construção na obra de Cabral, e a impossibilidade de separar aquelas duas dimensões, esse mesmo Cabral que descarna a realidade pela consciência da palavra poética e constrói sua poética a partir de um aprendizado de des-participação, em que segue Drummond:

Cruza-se com Drummond no campo de possíveis do projeto: entra na participação quando o poeta mineiro dela vai saindo, desparticipando-se: entra na realidade nacional de país subdesenvolvido (mesmo fisicamente ausente em Espanha ou França, ou talvez por isso mesmo...), para dizer sim numa sala negativa. Começa tudo de novo, único modo de poder saber diferenciar novamente as palavras que, se são coisas, são também signos que transferem sentidos. Da flor passa à faca. E vai descascando a paisagem sub specie de paisagens e fatos, selecionando suas opções na medida mesma em que as descreve e organiza. (PIGNATARI, 2004, p. 114)

O outro exemplo vem de Vagner Camilo, que, pela análise da "Divagação sobre as Ilhas", texto em prosa publicado por Drummond em 1952 - , demonstra como o poeta tensiona a relação entre engajamento e forma e recusa um compromisso ético que não seja igualmente poético:

Em Drummond, entretanto, essa tensão persiste, através da concepção dialetizante encarnada por sua ilha estrategicamente situada, de modo a lhe permitir, de um lado, proteger-se da retórica alienante e estéril em que incorreu a geração de 45 no seu intento de firmar o território autônomo da poesia, em resposta à especialização do trabalho artístico então em curso; de outro, escapar ao comprometimento político-partidário de muitos dos artistas participantes que se sujeitavam ao dogma jdanovista. (CAMILO, 2001, p. 96) 
Assim, na própria reunião de arte e política, como afirma Silviano Santiago, é que nossos melhores escritores modernistas encontram seu modo de ser:

No século 20, os nossos melhores livros apontam para a Arte, ao observar os princípios individualizantes, libertadores e rigorosos da vanguarda estética europeia, ao mesmo tempo em que apontam para a política, ao querer denunciar pelos recursos literários não só as mazelas oriundas do passado colonial e escravocrata da sociedade brasileira, mas também os regimes ditatoriais que assolam a vida republicana. A atividade artística do escritor não se descola de sua influência política; a influência da política sobre o cidadão não se descola da sua atividade artística. (SANTIAGO, 2004, p. 66)

O diagnóstico de Silviano Santiago, na esteira dos outros dois analistas, mesmo não se dirigindo a uma autora contemporânea, ilumina com precisão o livro de Maria Amália Dalvi, e desvela a tradição sobre a qual se apoia a poesia da escritora. Se antes mencionei a figura importante de Décio Pignatari, lembro que uma das formas de se compreender a poesia brasileira desse começo do século XXI está em perguntar como cada poeta supera, ou não, o duplo legado da Poesia Concreta e da Poesia Marginal, as duas poéticas complementares que se fizeram onipresentes no último quartel do século XX (das quais Paulo Leminski apareça talvez como a mais fulgurante síntese) e que moldaram em grande parte a "metapoesia das coisas" que parece ser a tônica da poesia dos últimos vinte anos. Se essa pergunta permanece, e se a caracterização anfíbia feita por Silviano pode ser vista na poesia de Dalvi, podemos talvez concluir que a poesia de Maria Amélia busca o seu caminho a partir de um salto para trás, que sobrevoa o complexo concreto-marginal da tradição recente em busca de precursores entre os modernistas construtivo-engajados. Com certeza, esse salto não tem nada de conservador, uma vez que, se a inspiração parece vir de poetas como Drummond e Cabral, a realização da poesia de Dalvi deles se distancia por ser absolutamente contemporânea em seus temas e formas, o que não deixa de incluir a economia de meios advinda da poesia marginal e a atenção ao significante, marca concreta.

Se tomamos, como exemplo, um poema da seção Exercício, aquela onde a dimensão política funciona como motor, podemos ver ali mesmo os elementos construtivos operando, tal qual mostramos no início deste trabalho:

\section{PÁTRIA \\ aqui, tudo segue \\ ao contrário \\ (eu aguardo \\ meu retorno \\ aos ovários). \\ perdi o bonde \\ ou essa praga \\ pregressa}




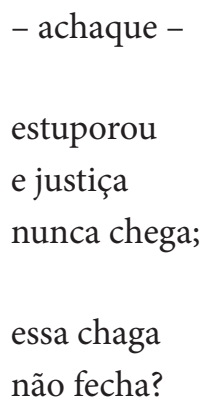

Depois do nosso percurso, o leitor já vê aí instantaneamente o mesmo obsedante tema da perda, assentado na repetição da célula fonética obstrutiva presente em PáTRia, ConTRário, aGuaRDo, PeRDi, PRaGa, PReGressa, esTuPoRou. A economia de meios é realmente notável, por exemplo na repetição estrutural das vogais fortes e átonas, cercadas das mesmas consoantes, que transforma a expressão "essa praga pregressa" em "essa chaga não fecha", verdadeira operação combinatória que faz um verso nascer do outro. Note-se, igualmente, a ocorrência de verdadeira palavra-valise, "achaque", no centro do poema, a qual condensa pela forma e pelo sentido toda a significação do texto. O poema se inicia com o advérbio "aqui', como a marcar, in media res, uma descrição geográfico-histórica. Esse mesmo "aqui" cria um caminho por "perdi” (pela rima), praga (através da célula sonora /pr/), para daí ir a "chega" e "chaga", ferida que descreve a pátria. Pois entre "aqui" e "chaga" está "aCHAque", composta pela junção das duas palavras anteriores, e se dá igualmente a ler como "acha que", sintagma que denuncia a chaga histórica como produto de desmando (opinião, improviso, descaso), ao mesmo tempo em que denuncia a perenidade da ferida, uma doença crônica, achaque.

Silviano Santiago, na sequência do texto antes citado, afirma que, na literatura brasileira, arte e política se dão as mãos para dizer que "educação", como alertava Anísio Teixeira, "não é privilégio": "caso a educação não tivesse sido privilégio de poucos desde os tempos coloniais, talvez tivéssemos podido escrever de outra maneira o panorama da literatura brasileira contemporânea" (SANTIAGO, 2004, p. 72). O diagnóstico do crítico amarra as pontas da relação entre arte e política na literatura brasileira. Para o crítico, a nossa compósita relação de arte e política possui um viés pedagógico, em processo de auto atribuição de tarefa condutora por parte do intelectual e do artista. No modernismo brasileiro, tudo se passa então como se o artista, com sua consciência social auto atribuída, sentisse uma obrigação de não ser apenas artista, mas ao contrário, de portar-se como reformador social, carregando o mundo nos ombros, para usar a expressão de Carlos Drummond de Andrade. Esse apontamento nos permite voltar à educação como motivo ordenador da poética de Maria Amélia Dalvi.

E aqui quero justapor aquela que me parece ser imagem central da poesia de Maria Amélia Dalvi - a montanha ao lado da água, que vimos desde o começo deste texto (em poemas como Montanha, Beira Mar e Penedo) - a uma imagem vinda de uma fonte aparentemente estranha à sua poética estético-engajada, mas que, exatamente pela distância, pode talvez iluminar um pouco mais o texto. A força da imagem literária está em que suas relações com o objeto não se constroem por espelhamento, e por isso a distância, ao invés de afastar, pode muitas vezes revelar. 
A montanha diante da água é uma das imagens exemplares do Livro das Mutações, o I Ching, esse antigo compêndio chinês em que o conhecimento aparece na imagética da natureza, de resto um procedimento consagrado na própria história da lírica. Trata-se, portanto, de um conhecimento de ordem poética, o que permite aqui aproximá-lo do modo de construção de uma autora de poesia, sem que se trate de fazer teoria aplicada. Nesse livro, que opera por imagens, os sessenta e quatro arquétipos de sentido, os hexagramas, se compõem da justaposição, dois a dois, de oito trigramas básicos. Sigo aqui as indicações de Richard Wilhelm, possivelmente o mais reconhecido dos comentadores modernos do texto (WILHELM, 1995, p. 12). Um daqueles trigramas é a "A Quietude", cuja imagem é a Montanha, Kên, e cujos atributos são firmeza e calma, mas igualmente dureza, rudeza e obstinação (se o leitor se lembrar do verso do poema Montanha, que diz “toda a rudeza, na verdade, é calma”, estará seguindo o meu raciocínio); outro trigrama se denomina "O Abismal", cuja imagem é a água, K’an, e cujo atributo é o de ser perigoso. Quando se justapõe a Água ao pé da Montanha, tal como na imagem recorrente do livro de Dalvi, encontra-se o hexagrama de número 4, nomeado Imaturidade (Insensatez Juvenil), que tem na educação o seu tema. Assim se inicia o texto-comentário associado ao hexagrama: "Não sou eu quem procura o jovem insensato; o jovem insensato é quem me procura" (WILHELM, 1995, p. 24). Wilhelm comenta desta maneira a passagem:

O texto aconselha tanto o professor como o aluno. A juventude deve ter consciência de sua falta de experiência, e deve procurar um preceptor. Sem esta modéstia, sem esta respeitosa aceitação do preceptor, não há garantia de que o jovem seja atendido com a necessária receptividade. $\mathrm{O}$ preceptor deve esperar até ser procurado, em vez de se oferecer espontaneamente: esta é a relação correta na educação. As respostas de um preceptor a um discípulo devem ser claras e definitivas, servindo tanto para a solução de dúvidas quanto como base de decisões. (WILHELM, 1995, p. 24)

As posições do sábio e do estudante são intercambiáveis, como as da montanha e do mar, um diante do outro. Pode-se dizer igualmente que elas se aplicam a um mesmo indivíduo, que, para se tornar sábio, deve permanecer sempre estudante, como no dito rosiano expresso pelo personagem Riobaldo, em Grande sertão: veredas, "Mestre não é quem sempre ensina, mas quem de repente aprende". Essa imagem fala menos de mestre e aprendiz do que da própria relação de ensino e aprendizado. O antigo texto do I Ching assim descreve a imagem do hexagrama: "O sábio assemelha-se à límpida fonte a fluir da montanha: meticuloso, franco e calmo. E o comentador explica: Semelhante à grande quietude de uma montanha à beira do abismo, ele (o sábio) atinge a tranquilidade diante do perigo" (WILHELM, 1995, p. 24). Desta forma, por um improvável caminho, que não esconde o salto metafórico, podemos dizer que, na poesia de Dalvi, a obsessão com a pedra diante do mar, com a quietude em face do abismo e do fluxo, reitera o profundo e interminável processo de educação que move o eu-lírico, o qual se expressa na aproximação de arte e política. Estamos então diante de uma educação pela pedra no meio do caminho? Apenas em parte. Na poética de Dalvi não há pedra sem água. Dessa pedra nasce uma fonte de contínuo fluxo, que evita a estagnação e contorna todos 
os obstáculos em direção ao mar abissal. Se a melhor tradição da poesia brasileira se revela na poesia de Maria Amélia Dalvi, ela vem modificada pela voz pessoal da autora, que parte da tradição para inventar o seu novo, no qual a tradição não é efeito de superfície, mas conhecimento internalizado.

Volto ao começo deste texto para rever o ponto de partida depois do percurso feito. Para a concepção romana de conhecimento, expressa tanto em Horácio quanto em Cícero, a arte existe ut delectet, ut moveat e ut doceat, para deleitar, comover e educar. O problema dessa concepção, sabemos desde Platão, está na submissão da arte a uma função externa ao seu campo autônomo. Alcir Pécora, em um debate sobre as relações entre literatura e ensino (a área de trabalho intelectual da poeta Maria Amélia Dalvi), coloca a questão de maneira que nos ajuda a compreender a poesia da autora. Em sua intervenção, ele faz uma defesa veemente da irredutibilidade da literatura a qualquer operação alheia ao ato produtivo. A arte, diz o crítico, pode ensinar do que não se sabia antes do impacto do objeto artístico. Até aí, nada contra a ideia de conhecimento. Mas, argumenta o crítico:

O problema começa quando se começa a pensar que ela possa ser traduzida ou mesmo dignificada por uma ideia, uma teoria ou conhecimento que formule a sua essência ou a sua finalidade. Porque a ideia de conhecimento supõe a ideia de propósito, de constituição racional de um argumento, cujo andamento ordenado gera ou tende a um conceito. Ou seja, a ideia de conhecimento está assentada sobre esse tipo de operação que tende a abstratizar a Literatura, e não acho que ela ganhe com isso. (PÉCORA, 2014, p. 308)

Será isso o que faz Dalvi? Entendo que não, uma vez que, como vimos, é antes como forma que o conhecimento ou a educação aparecem na sua poesia. Podemos dizer que a poesia de Dalvi não peca pelo sociologismo que abate muitos escritores brasileiros. Ao contrário, é a forma o que ressalta de seus textos e que comunica o sentido. O mesmo Alcir Pécora nos esclarece:

O propósito, quando se fala em obra de arte, se realiza no ato de criação dela. Essa criação não precisa ser ex nihilo, pode significar também a escolha de um tópico da tradição para dispô-lo de uma forma particular, única. Mas, em qualquer caso, sempre implica um ato efetivamente feito na direção da constituição de uma forma - que quando é bem sucedida, agora sim, passa a ser determinada pelos seus próprios termos. Quero dizer, não se pode pensar a arte sem a correspondente produção de uma forma objetiva, cabal, que se impõe sobre o seu auditório. (PÉCORA, 2014, p. 308)

Com certeza, a poesia de Dalvi não nasce do nada. Ela toma como tópico da tradição exatamente a possibilidade instrutiva da arte, para com ela construir a sua forma particular, única, que, a meu ver, é muito bem-sucedida. Silviano Santiago, no texto antes citado, termina por lamentar que, na história da sociedade e da cultura brasileira, a literatura não tenha podido dispensar o ut doceat, para ficar apenas no deleite e na comoção. Maria Amélia Dalvi, ao contrário, assume esse terceiro termo da poética horaciana como o seu mote. Mas, mais do que o mote, importa a sua glosa, forma poética que faz da estreante um mestre que, a todo o tempo, aprende, e com quem nos deleitamos e comovemos. 


\section{REFERÊNCIAS}

CAMILO, Vagner. Da Rosa do Povo à Rosa das Trevas. São Paulo: Ateliê Editorial, 2001, Parte 1, Cap. 3: “ Uma Retirada Estratégica”, p. 89-102.

DALVI, Maria Amélia. Poema algum basta. Vitória: Cousa, 2019, 100 p.

FERREIRA, António. Carta XII a Diogo Bernardes. In: SPINA, Segismundo. Introdução à poética clássica. São Paulo: FTD, 1967, p. 11.

JAKOBSON, Roman. Linguística e comunicação. Trad. Izidoro Blikstein e José Paulo Paes. São Paulo: Cultrix, 1985 .

MACIEL, Bruno, MONTEIRO, Darla, AVELAR, Júlia, BIANCHET, Sandra (orgs.). Epistula ad Pisones - edição bilíngue. Belo Horizonte: Faculdade de Letras da UFMG/VivaVoz, 2013, 54 p.

PECORA, Alcir. Literatura como ato irredutível ao conhecimento. Remate de Males, Campinas-SP, (34.2): Jul./Dez. 2014.

PIGNATARI, Décio. A situação atual da poesia no Brasil. In: Contracomunicação. 3 ed. Cotia (SP): Ateliê Editorial, 2004, p. 99-120.

SANTIAGO, Silviano. Uma literatura anfíbia. In: O cosmopolitismo do pobre: crítica literária e crítica cultural. Belo Horizonte: Editora UFMG, 2004, p. 64-73.

WILHELM, Richard. O pequeno I Ching. Trad. Alayde Mutzenberger. São Paulo: Pensamento, 1995. 